\title{
Impact of surface wind biases on the Antarctic sea ice concentration budget in climate models
}

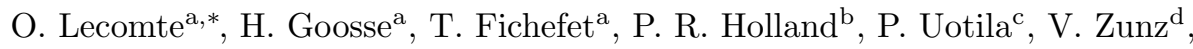 \\ N. Kimura ${ }^{\mathrm{e}}$ \\ ${ }^{a}$ Université catholique de Louvain, Earth and Life Institute, Georges Lemaître Centre for \\ Earth and Climate Research (UCL-ELIC-TECLIM), Louvain-la-Neuve, Belgium \\ ${ }^{b}$ British Antarctic Survey (BAS), Cambridge, United Kingdom \\ ${ }^{c}$ Finnish Meteorological Institute (FMI), Helsinki, Finland \\ ${ }^{d}$ Rayference, Brussels, Belgium \\ ${ }^{e}$ National Institute of Polar Research, Tachikawa, Japan
}

\begin{abstract}
We derive the terms in the Antarctic sea ice concentration budget from the output of three models, and compare them to observations of the same terms. Those models include two climate models from the 5th Coupled Model Intercomparison Project (CMIP5) and one ocean-sea ice coupled model with prescribed atmospheric forcing. Sea ice drift and wind fields from those models, in average over April-October 1992-2005, all exhibit large differences with the available observational or reanalysis datasets. However, the discrepancies between the two distinct ice drift products or the two wind reanalyses used here are sometimes even greater than those differences. Two major findings stand out from the analysis. Firstly, large biases in sea ice drift speed and direction in exterior sectors of the sea ice covered region tend to be systematic and consistent with those in winds. This suggests that sea ice errors in these areas are most likely wind-driven, so as errors in the simulated ice motion vectors. The systematic nature of these biases is less prominent in interior sectors, nearer the coast, where sea ice is mechanically constrained and its motion in response to the wind forcing more depending on the model rheology. Second, the intimate relationship between winds, sea ice drift and the sea ice concentration budget gives insight on ways to categorize models with regard to errors in their ice dynamics. In exterior regions, models with seemingly too weak winds and slow ice drift consistently yield a lack of ice velocity divergence and hence a wrong wintertime sea ice growth rate. In interior sectors, too slow ice drift, presumably originating from issues in the physical representation of sea ice dynamics as much as from errors in surface winds, leads to wrong timing of the late winter ice retreat. Those results illustrate that the applied methodology provides a valuable tool for prioritizing model improvements based on the ice concentration budget-ice
\end{abstract}

\footnotetext{
${ }^{*}$ Corresponding author

Email address: olivier.lecomte@uclouvain.be (O. Lecomte)
}

Preprint submitted to Ocean Modelling

August 3, 2016

(C) 2016. This manuscript version is made available under the Elsevier user license http://www.elsevier.com/open-access/userlicense/1.0/ 
drift biases-wind biases relationship prevailing in the simulation of Antarctic sea ice over the last decades.

Keywords: , Antarctic, sea ice, wind, models

2015 MSC: 12-01, 99-00

\section{Introduction}

In general, coupled climate models fail to reproduce the observed expansion of Antarctic sea ice during the recent decades (Turner et al. 2013). This may be due to the large role of interannual variability in this increasing trend (Zunz 5 et al., 2013: Mahlstein et al. 2013). Nevertheless, most models from the 5th Coupled Model Inter-comparison Project (CMIP5, Taylor et al., 2012) systematically overestimate the interannual variance of the winter Antarctic sea ice extent, and show large biases in the representation of the sea ice mean state around Antarctica (Zunz et al., 2013). This suggests that some sea ice physical

10 properties or some atmospheric and oceanic processes in the Southern Ocean are systematically misrepresented in these models. Improving current models so as to simulate a realistic sea ice mean state seems thus a priority, since it is the basis for adequately reproducing correct variability and trends.

However, determining the origins of the biases in the Antarctic sea ice state in models is not straightforward. A common method is to compare various model variables to observations, whenever and wherever available, and analyze the differences to find connections. However, the correlation between biases in different variables does not necessarily provide information on the cause-to-effect relationship between them, and the sources of problems potentially revealed by

20 this method are often hidden by the models' complexity (Randall et al. 2007). n An alternative to this is, for instance, the methodology proposed in Holland and Kwok (2012). They have separated the local sea ice concentration budget into four terms, including the net total ice concentration change during a given period, the contributions of advection and divergence to this change 25 and a residual accounting for the thermodynamic growth and melt of sea ice. Consequently, the evaluation is not focused on single variables such as sea ice concentration or velocity, but the whole chain of processes controlling the evolution of sea ice is evaluated. Estimating the combined contribution of advection, divergence and deformation to sea ice concentration changes within "dynam-

so ical tendency" variables directly calculated during a simulation is a standard diagnostic in some models (e.g., in CICE4/CCSM4, Bitz et al., 2005; Landrum et al., 2012). However, the use of the method proposed here on a model output in order to compare the simulated ice concentration budget to observations was made only recently in Uotila et al. (2014. Australian ACCESS model). It

35 was proven to be very relevant for evaluating the model ability to simulate the respective contributions of dynamics and thermodynamics to sea ice concentration changes in the Southern Ocean. Discrepancies between the observed and modeled sea ice concentration budgets were found, especially near the Antarctic 
coast and the ice edge, where the simulated sea ice motion was more convergent and faster than observed, respectively.

The conclusions of Uotila et al. (2014) were sensitive to the selected model configuration. A first goal of this study is to test the reproducibility of their results by applying the sea ice concentration budget to several models showing contrasted biases with respect to the mean sea ice state. Consequently,

45 the outputs from two models from the CMIP5 archive and an ocean-sea ice coupled model forced by atmospheric reanalyses are described in the following section. These models were chosen, as further explained below, because they span an interesting range of model configurations (forced atmosphere vs. fully coupled model) and behaviors. Indeed, each of these models has its own and

${ }_{50}$ distinct biases with respect to observations. One climate model systematically overestimates the sea ice extent throughout the year, while the other features the opposite, and the ocean-sea ice model yields a too weak seasonality around a realistic yearly mean ice extent. Applying the sea ice concentration budget to those models thus gives insight on: 1 . the thermodynamic vs. dynamic origins 55 of the sea ice concentration errors, and 2. whether these models share common physical problems in spite of their different biases with respect to the sea ice mean state at the hemispheric scale.

A second goal is to extend the analyses proposed in Uotila et al. (2014) and further assess the impact of wind biases on the ice dynamics in model outputs.

60 This will be achieved by comparing the simulated sea ice drift and wind fields to satellite observations and reanalyses.

The methodology for all performed analyses is provided in section 3 . The concentration budget is then presented in section 4, with a particular focus on the regional variability of the wind-sea ice motion relationship. In section 5 , 65 the main results are discussed before summarizing the conclusions of this work, including perspectives on the way to select or improve models based on their skills in the Southern Ocean.

\section{Model description}

\begin{tabular}{|c|c|c|c|c|}
\hline Model Name & $\begin{array}{l}\text { Atmospheric } \\
\text { component }\end{array}$ & $\begin{array}{l}\text { Oceanic } \\
\text { component }\end{array}$ & $\begin{array}{l}\text { Sea ice } \\
\text { component }\end{array}$ & Reference \\
\hline $\mathrm{CCSM}_{4}{ }^{1}$ & $\begin{array}{l}\text { CAM4; } \\
26 \text { vertical levels, } \\
1.25^{\circ} \times 0.9^{\circ}\end{array}$ & $\begin{array}{l}\text { POP2; } \\
60 \text { vertical levels, } \\
1.11^{\circ} \times(0.27-0.54)^{\circ}\end{array}$ & $\begin{array}{l}\text { CICE4; } \\
1.11^{\circ} \times \\
(0.27-0.54)^{\circ}\end{array}$ & Gent et al. $(\overline{2011})$ \\
\hline $\begin{array}{l}\text { IPSL }^{2} \\
\text { (IPSL-CM5A } \\
-\mathrm{MR})\end{array}$ & $\begin{array}{l}\text { LMDZ4 v5; } \\
39 \text { vertical levels, } \\
\sim 1.25^{\circ} \times 2.5^{\circ}\end{array}$ & $\begin{array}{l}\text { NEMO v2.3; } \\
31 \text { vertical levels, } \\
\text { ORCA-2 }^{\circ}\end{array}$ & $\begin{array}{l}\text { LIM2; } \\
\text { ORCA- } 2^{\circ}\end{array}$ & http://icmc.ipsl.fr/ \\
\hline NEMO-LIM3 & $\begin{array}{l}\text { Prescribed. } \\
\text { See section } 2\end{array}$ & $\begin{array}{l}\text { NEMO v3.5; } \\
46 \text { vertical levels, } \\
\text { ORCA-1 }^{\circ}\end{array}$ & $\begin{array}{l}\text { LIM3; } \\
\text { ORCA-1 }^{\circ}\end{array}$ & $\begin{array}{l}\text { Barthélemy et al. } \\
(2015)\end{array}$ \\
\hline Modeling ce & ${ }^{1}$ National Cent & $\begin{array}{l}\text { r Atmospheric Rese } \\
\text { Ion Laplace. }\end{array}$ & (NCAR) & \\
\hline
\end{tabular}




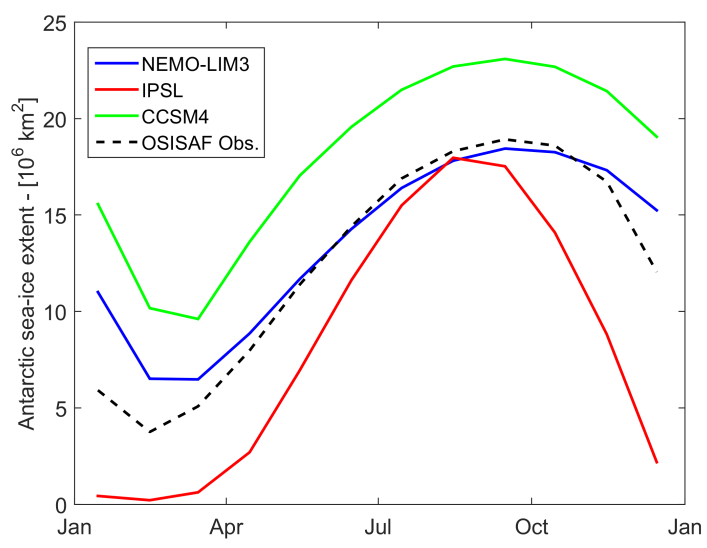

Figure 1: Mean seasonal cycle of Antarctic sea ice extent over 1992-2005, as observed (OSISAF 2010) and simulated by the three models: NEMO-LIM3, IPSL (IPSL-CM5A-MR) and CCSM4. Extents are calculated as the total area of oceanic grid cells in the Southern Ocean with an ice concentration larger than $15 \%$.

As described in Table1 1 simulations from three models are analyzed in this study. The first two are historical simulations performed by the CCSM4 and IPSL-CM5A-MR (hereafter referred to as IPSL) coupled climate models, from the CMIP5 multi-model ensemble: http://pcmdi9.1lnl.gov/. The sea ice component in CCSM4 is the LANL Community Ice CodE version 4 (CICE4; Hunke and Lipscomb, 2010), which uses the ice thickness distribution formalism (ITD; Thorndike et al., 1975) and the elastic-viscous-plastic rheology (EVP; Hunke and Dukowicz, 1997) for sea ice dynamics. The corresponding components in IPSL are the Louvain-la-Neuve sea Ice Model version 2 (LIM2; Fichefet and Morales Maqueda, 1997) and the viscous-plastic (VP) constitutive law of Hibler (1979), respectively. The third model is the ocean-sea ice global coupled

so model NEMO-LIM3 (Nucleus for European Modelling of the Ocean - Madec 2008 Louvain-la-Neuve sea Ice Model version 3 - Vancoppenolle et al., 2009). The model version used here is described in detail in Barthélemy et al. (2015). Contrary to the first two ones, this model is driven by a prescribed atmosphere, using the NCEP/NCAR surface air temperature and wind reanalyses (Kalnay

85 et al. 1996) and monthly climatologies of relative humidity, cloudiness, precipitation and river runoffs as forcing fields. Surface heat fluxes computations are based on Goosse (1997). Like CICE4, LIM3 includes, in particular, the ITD formalism and the EVP rheology.

Historical simulations from CMIP5 models are performed through 1850-2005,

90 while the NEMO-LIM3 simulation is run over 1948-2012. Therefore, given the time coverage of the observational reference study (1992-2010; Holland and Kwok, 2012), the sea ice concentration budget in models is restricted to the intersection interval of these three time periods: 1992-2005. 
To have a first overview of the representation of the Southern Ocean sea ice in those three models, the mean annual cycles of simulated and observed ice extents over the period 1992-2005 are shown in Fig. 1. This figure clearly underlines the systematic biases in the simulations performed with CMIP5 models, with CCSM4 and IPSL overestimating and underestimating the ice extent by about , $5 \times 10^{6} \mathrm{~km}^{2}$, respectively, for almost all months (Landrum et al., 2012, Zunz

100 et al. 2013). Although NEMO-LIM3 significantly overestimates the ice extent minimum due to insufficient summer melting rates, it is closer to observations. This is to be expected somehow, since the models used to produce atmospheric reanalyses use the observed sea ice cover and sea surface temperatures as lower boundary conditions. In other words, reanalysis-forced models are more likely 105 to simulate the ice extent correctly compared to fully coupled ones, since the information about the observed ice cover is to some extent embedded into the reanalyses. Thus, those three models present different characteristics in terms of configurations (prescribed atmosphere vs. fully coupled model) and errors with respect to the sea ice mean state they are able to simulate. Considering 110 that the sea ice concentration budget analysis is model-specific (Uotila et al. 2014), NEMO-LIM3, IPSL and CCSM4 provide one interesting set of models to be tested using the methodology described below.

\section{Methods}

\subsection{Sea ice concentration budget}

The first analysis applied to the aforementioned model data is the sea ice concentration budget from Holland and Kwok (2012). The evolution equation of ice concentration can be written as:

$$
\frac{\partial A}{\partial t}+\mathbf{u} \cdot \nabla A+A \nabla \cdot \mathbf{u}=f-r
$$

where $\mathrm{A}$ and $\mathbf{u}$ are the ice concentration and velocity, respectively, either taken from model outputs or retrieved from Special Sensing Microwave/Imager (SSMI) data (NASA-Team-1 algorithm - Cavalieri et al., 1996, updated yearly, for ice concentration; Comiso et al., 2011 and Kwok et al., 1998, for ice velocity). Note that an alternative ice concentration data product, retrieved using the so called "bootstrap" algorithm (Comiso, 2000, updated 2015), is available. Although this would be out of the scope of our study, quantifying the sensitivity of the observed ice concentration budget to the selected dataset would be instructive. On the left hand side of the equation, the first term represents the sea ice concentration change rate. The second and third terms are the respective contributions of ice advection and divergence to the ice concentration change. On the right side, $f$ is the ice concentration change from freezing and melting, and $r$ the one from mechanical ice redistribution processes, such as ridging or rafting. After reorganizing the equation and integrating it between times $t_{1}$ and $t_{2}$, it becomes:

$$
\int_{t_{1}}^{t_{2}} \frac{\partial A}{\partial t} d t=-\int_{t_{1}}^{t_{2}} \mathbf{u} \cdot \nabla A d t-\int_{t_{1}}^{t_{2}} A \nabla \cdot \mathbf{u} d t+\int_{t_{1}}^{t_{2}}(f-r) d t
$$




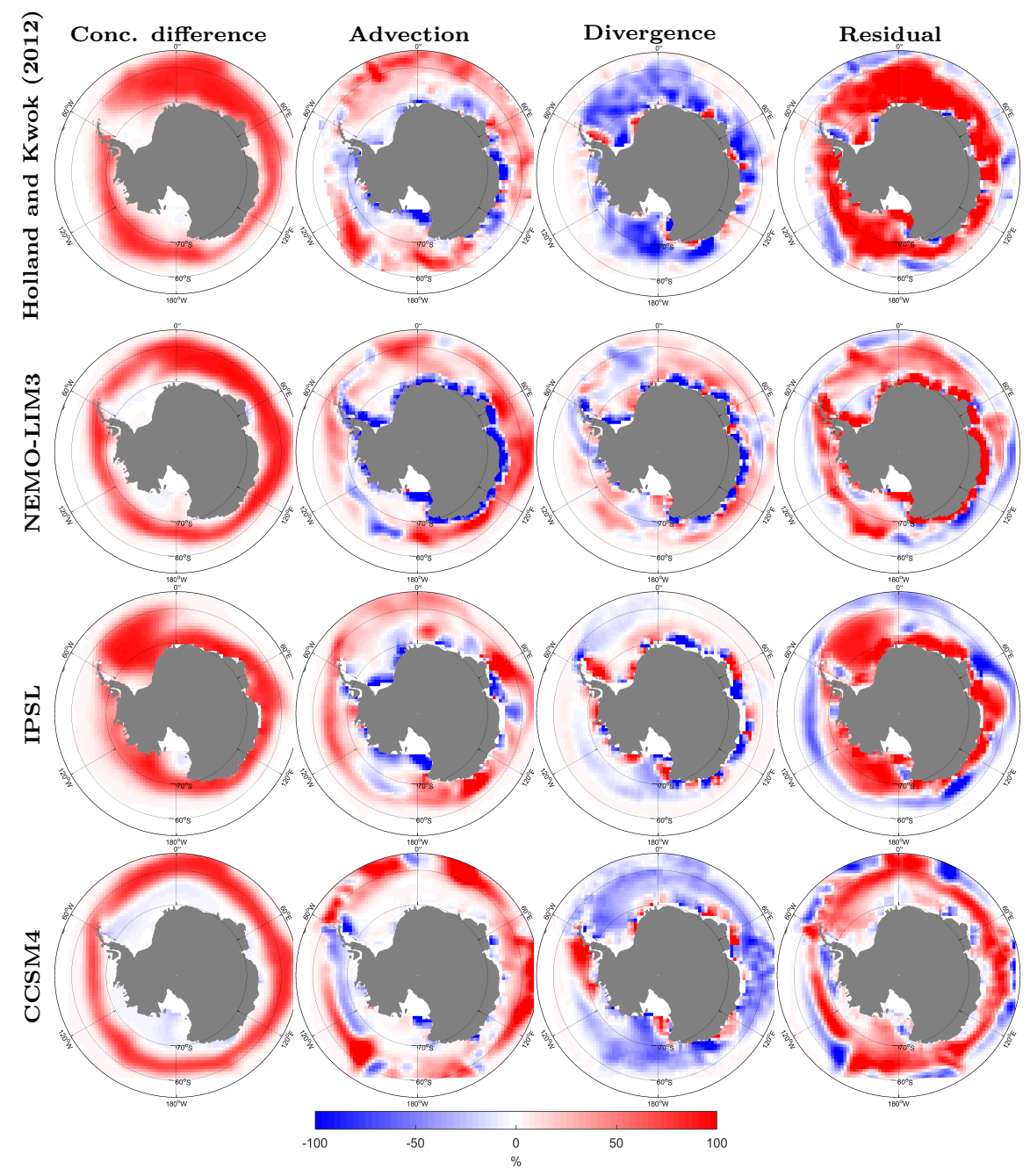

Figure 2: Antarctic sea ice concentration budget components over April-October 1992-2010 from Holland and Kwok (2012) and as computed over April-October 1992-2005 (CMIP5 historical runs stop in 2005) for the selected three models. The leftmost panels display the mean observed April-October ice concentration difference $\left(\int \frac{\partial A}{\partial t} d t\right)$. "Advection" is the mean ice concentration change from ice advection $\left(-\overline{\int \mathbf{u} \cdot \nabla A d t}\right)$, quantifying whether ice motion tends to import (red) or export (blue) sea ice locally. "Divergence" is the mean ice concentration change from ice velocity divergence $\left(-\overline{\int A \nabla \cdot \mathbf{u} d t}\right)$, describing whether the pack is opening (divergence, blue) or closing (convergence, red). Finally, panels on the right show the mean ice concentration change from residual freezing $\left(\overline{\int f t}\right)$ for which, as in other panels, blue (red) areas correspond to negative (positive) contributions to ice concentration changes. As explained in Holland and Kwok (2012), all budget terms are scaled between -100 and 100\% of the grid cell area, but they can actually reach values smaller and greater than those lower and upper bounds, respectively. For instance, freezing higher than $100 \%$ in a grid cell means that the coverage of ice formed during the calculation period is larger than the total surface of this cell. 
The last term on the right hand side is calculated as a residual component from all the others, that can be calculated directly from model outputs or observational sea ice fields. This last term could also be diagnosed from model outputs but is computed as for the observations for consistency. As the Antarctic sea ice drift tends to be divergent, $f$ (melting or freezing in open water) is expected ${ }_{120}$ to be much larger than $r$ in magnitude (Uotila et al., 2014). Thus, we hereafter consider $r$ as negligible and refer to the last term alternatively as the "residual" or "freezing"term. The other terms, from the left to the right, are referred to as "concentration change", "advection" and "divergence". By integrating the daily sea ice concentration budgets through April-October for each year from 1251992 to 2005 and for each cell of model or observation grids, 14 spatial fields are obtained for each term. During summer, the motion-tracking procedure is less accurate due to the ice surface melt and no budget can be performed from observations. Taking the average of these fields over the 14 years finally provides the mean sea ice concentration budget over April-October 1992-2005, as displayed in Fig. 2

To produce these fields and compare model results with observations, every calculation is made on the $100 \times 100 \mathrm{~km}^{2}$ grid used in Holland and Kwok (2012). This means that all the simulated ice velocities and concentrations had to be interpolated on this grid. The other possible method to compute the different 135 budget terms is to do so on the original model grids, and then interpolate them onto the observation grid. The first one ensures a similar methodology for model results and observations and thus a homogeneous comparison between them, whereas the second preserves accuracy and internal consistency with regard to the models' budgets themselves. Nevertheless, both methods appear to provide very similar results here (see Supplementary Material), showing that the loss of accuracy caused by the intermediate rotation and interpolation of the simulated ice drift onto the observation grid is not a critical issue. Thus, we choose to guarantee a fair model-observation comparison and retain the first method. Additionally, a low pass filter is applied to all terms by replacing the values at 145 every grid point by the mean value of a 9-cell square centered on this point, following Holland and Kwok (2012). Although not specifically required for the model outputs, this smoothing is necessary for the observation based results in order to reduce the spatial noise in the derivatives.

Fig. 2 (top panels) illustrates the sea ice concentration budget applied to satellite observations and, in particular, the pairwise divergence-freezing and advection-melting relationships. Close to the continent and in the central ice pack, strong freezing rates are maintained by velocity divergence, because openings in the pack during this time of the year favor new ice production, while advection exports sea ice in outer and warmer regions where sea ice melts. Nar155 rowing the integration over April-June yields a smaller magnitude of the advection and divergence contributions to the ice concentration difference, as opposed to the larger freezing rates nearly everywhere around Antarctica, showing the thermodynamics-dominated ice growth during this period. 


\subsection{Ice drift and wind analyses}

The sea ice concentration budget is a valuable tool for separating the dynamical and thermodynamical contributions to sea ice concentration evolution and evaluating a model's ability to simulate regional variations consistently with observations (Uotila et al., 2014). However, assessing why the advection or divergence is locally wrong requires one to evaluate the simulated ice velocity vectors. Since the ice motion is in large part driven by the wind, evaluating wind speed vectors is also necessary. This two-step evaluation of ice and wind velocities ultimately allows attributing ice velocity errors to either the sea ice model physics, i.e., rheology or boundary layer physics (e.g., surface drag coefficient or turning angle), wind forcing errors, or both.

170 In section 4, ice drift and wind vectors are evaluated. Simulated ice motion vectors are compared against both those of the Polar Pathfinder Daily 25 km EASE Grid satellite product (Fowler et al. 2013) and of the Advanced Microwave Scanning RadiometerEarth Observing System (AMSR-E) data (Kimura et al. 2013). Note that those products are different from the one used for com175 puting the observed sea ice concentration budget described above. This was done only for practical reasons, as the ice motion observational product used in Holland and Kwok (2012) is not yet available publicly. It is important to note as well that any sea ice velocity satellite product suffers from relatively large uncertainties. Fig. 3 shows the Fowler et al. (2013) and Kimura et al. (2013) April-October mean ice drift vectors over 2003-2010. The second ice drift product features ice velocity norms $2.5 \mathrm{~cm} \mathrm{~s}^{-1}$ larger in average, with the largest differences in the Weddell, Indian and Pacific free drift regions of the Southern Ocean. This is consistent with previous studies reporting the Fowler et al. (2013) data to be too slow (Heil et al., 2001). Ice drift directions, specifi-

185 cally shown later in section 4 , are in good agreement in the two products except again in the Indian and Pacific sectors. When comparing modeled ice velocities to such observational datasets, one must then keep those differences in mind. Because the ice motion is relatively slow in the Fowler et al. (2013) product, applying the ice concentration budget on this dataset provides results that are not consistent with Holland and Kwok (2012). On the other hand, the budget analysis using ice motion vectors from Kimura et al. (2013) is currently under investigation and give results that are in better agreement with Holland and Kwok (2012) (Holland and Noriaki, Submitted). For those reasons, we made the choice of keeping the results from Holland and Kwok (2012) in our present

195 analysis, but we still compare the modeled ice drift vectors to the two satellite datasets at our disposal.

Simulated wind speed in coupled models is evaluated using both the NCEP/ NCAR surface winds that drive the NEMO-LIM3 model and ERA Interim reanalyses (Dee et al., 2011). The associated intercomparisons for sea ice drift and wind direction (velocity vector orientation) are then presented in section 4.3. Going northward from the Antarctic coast, the wind direction shifts from easterly to westerly. So as to distinguish these regimes in the analyses, a separation of the domain is made and presented in Fig. 4. The sea ice covered 


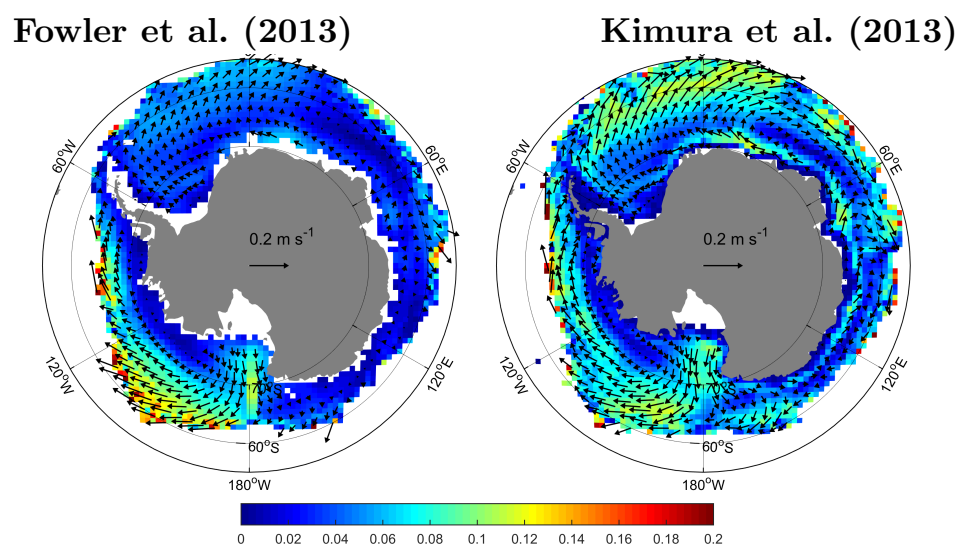

Figure 3: Mean sea ice motion vectors over April-October 2003-2010, for both the Fowler et al. (2013) and Kimura et al. (2013) observational products. The 2003-2010 averaging period corresponds to the one when Kimura et al. (2013) ice motion vectors are available. The color scale shows the norm of ice velocity, in $\mathrm{m} \mathrm{s}^{-1}$.

region of the Southern Ocean is split zonally into its different sectors (Weddell Sea, Indian sector, Pacific sector, Ross Sea and Bellingshausen-Amundsen Seas) and meridionally into interior and exterior areas representative of prevailing easterly and westerly wind regions, respectively. The limit between the interior and exterior regions is derived from the mean NCEP/NCAR surface wind fields over April-October 1992-2005, by considering the circle that best fits to the changes in wind direction in all sectors. For the sea ice dynamics, this meridional separation additionally enables to make the distinction between the compact inner ice pack where sea ice undergoes large mechanical constraints and marginal zones where it is presumably in free drift. Those regions are likely to be characteristic of two dissimilar ice motion regimes for which the relative

215 importance of the sea ice rheology and wind forcing are different. Note that this interior/exterior division is stationary in our diagnostics while, in reality, it varies seasonally and interannually depending on the Southern Annular Mode trends (Marshall, 2003). For each single sector of this domain, the local average in norm and direction of ice motion and wind vectors from models, observations or reanalyses is computed through April-October 1992-2005 and compared to each other.

\section{Results}

\subsection{Sea ice concentration budget in models}

Fig. 2 also shows the four sea ice concentration budget terms for the three selected models. All components exhibit both a global qualitative agreement with observations and substantial regional discrepancies. Like in Holland and Kwok (2012) and Uotila et al. (2014), divergence and advection drive the freezing in the central ice pack and the melting near the ice edge, respectively. However, 


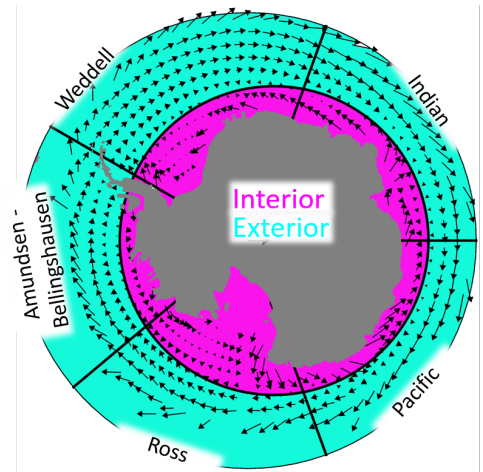

Figure 4: Limits of the regions that are used in the present evaluation of the modeled ice drift and wind. The Southern Ocean is split into five regions, namely the Weddell Sea, the Indian sector, the Pacific sector, the Ross Sea and the Amundsen-Bellingshausen Seas. Additionally, so as to differentiate the easterly from the westerly wind regimes in the analysis, the approximate geographical boundary between those regimes (based on the NCEP/NCAR $10 \mathrm{~m}$ wind velocity reanalyses in average over April-October 1992-2005, represented by black vectors) is used to delineate interior and exterior regions in each sector.

in terms of magnitude, essentially all models lack ice velocity divergence all around Antarctica (especially in exterior sectors) -NEMO-LIM3 and IPSL even exhibit areas with significantly convergent ice motion- whereas advection tends to be overestimated, especially in the Indian and Pacific sectors of the Southern Ocean. Such an overestimation of advection in the ice concentration budget close to the edge was also found in Uotila et al. (2014). However, their model did 235 not lack ice velocity divergence like it is the case here, which shows once again that such results are model-dependent. Consequently, the regions where the residual term (freezing) reaches its maximum values are not present in the right latitude band. As more sea ice remains in CCSM4 at the end of austral summer, the main freezing zones during the growth period are shifted northwards by approximately $5^{\circ}$ compared to observations. As opposed to this, the divergencemaintained freezing zone in IPSL does not extend north enough, especially in the Indian and Pacific sectors. The overall localization of these regions is better for NEMO-LIM3, but freezing contributions to ice concentration changes are clearly biased low (down to 50\%) due to the locally wrong velocity divergence.

245 In addition, NEMO-LIM3 features very strong divergence and freezing spots along almost the whole Antarctic coast, which is due to too strong offshore winds in the NCEP/NCAR reanalysis (Zhang et al., 2015), in turn affecting the ice motion.

\subsection{Ice drift and wind speed}

250 Fig. 5 provides first insights on how biases in the dynamic components of the sea ice concentration budget relate to ice drift errors in the models. It shows the relative error in ice drift speed as compared to the Fowler et al. (2013) dataset. Relative to this specific product, ice velocities are overestimated in many places 


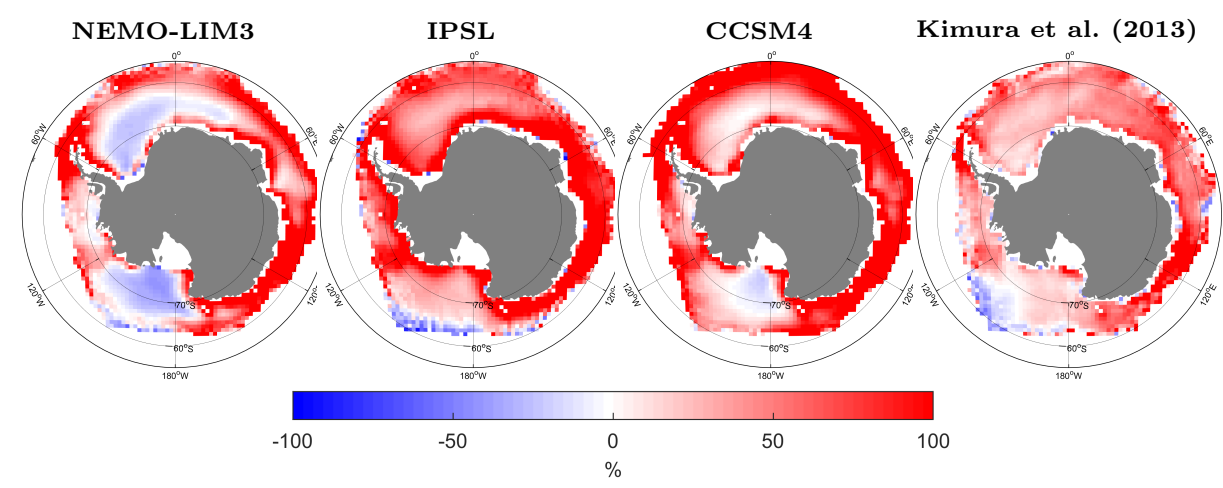

Figure 5: Mean relative error in ice drift speed, over April-October 1992-2005, for the three selected models, with respect to the Fowler et al. (2013) observational product. The last panel on the right displays the same map but for the Kimura et al. (2013) Fowler et al. (2013) average relative difference over April-October 2003-2010, the period over which Kimura et al. (2013) data are available.

and especially in the Indian and Pacific sectors in all models, where velocities reach two times their observational values. As discussed in Uotila et al. (2014), this may explain, at least in part, the above-mentioned too strong advection terms of the model ice concentration budgets in the corresponding regions. Linking this to sea ice velocity divergence, the models exhibiting the fastest ice drift seem to be those having the smallest underestimation of ice divergence. NEMO-LIM3 features the smallest mean ice velocity bias compared to Fowler et al. (2013), followed by IPSL and CCSM4, but also has the weakest sea ice velocity divergence among the chosen models. As opposed to this, CCSM4 exhibits the fastest ice drift, but the most realistic divergence term in the sea ice concentration budget. In the central Weddell and Ross Seas, however, the errors in ice velocities are sharply reduced and NEMO-LIM3 even underestimates the ice speed compared to Fowler et al. (2013). This suggests a specific interplay between the motion, rheology and mechanical wind forcing that is discussed in section 5 .

In order to quantify those biases regionally, Fig. 6 shows the April-October 1992-2005 temporal and spatial mean values and ranges of ice and wind speed for each sector defined in Fig. 4. Ice drift data from Kimura et al. (2013) are also included, although the averages are computed over a different 8-year span (20032010). Table 2 presents the speed ratios and vector direction angles between sea ice and wind speeds in all regions of the Southern Ocean and summarizes the relationship between ice drift and winds for each model.

In exterior sectors, NEMO-LIM3 and IPSL exhibit similar ice drift speeds, overestimating the Fowler et al. (2013) ice drift by 30 to $40 \%\left(\sim 4 \mathrm{~cm} \mathrm{~s}^{-1}\right)$, except in the Ross Sea where these two models agree well with observations. Consistently with Fig. 5, sea ice in CCSM4 drifts much faster and show large biases compared to Fowler et al. (2013) (from 70 to more than 100\% (8-15 cm $\mathrm{s}^{-1}$ ) in all sectors. Compared to Kimura et al. (2013), though, only CCSM4 ice 

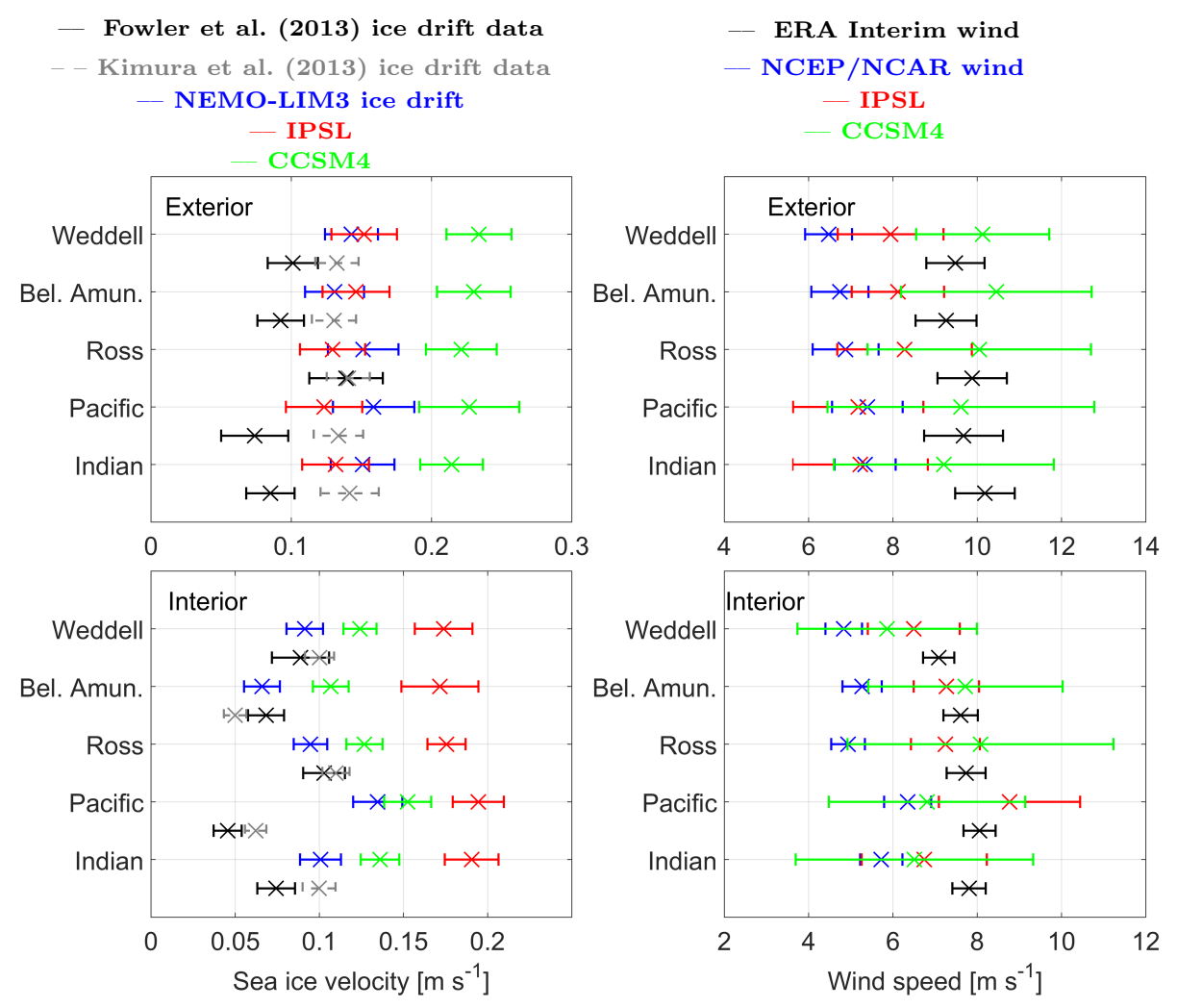

Figure 6: Mean value (crosses) and temporal variation range ( \pm 1 standard deviation intervals) of the sea ice drift speed and surface wind speed in each sector of the Southern Ocean, as defined in Fig. 4 The averages are performed over April-October 1992-2005, except for Kimura et al. (2013) ice drift data (2003-2010). The wind speeds displayed for NEMO-LIM3 are actually the NCEP/NCAR wind reanalyses used to force the model. Winds from the ERA Interim product are also added to provide a second benchmark. 
Table 2: Ice speed/wind speed ratio and ice drift-wind direction angle for the three models in all sectors, defined as in Fig. 4 The speed ratio in models is simply computed as the ratio of the ice speed over the wind speed in each sector in average over 1992-2005. KIM/EI stands for the speed ratio of the Kimura et al. (2013) ice drift speed over the ERA Interim wind speed. For the sake of readability, the standard deviations of the speed ratios for each model and region are not shown in the table, but they were calculated and are similar among models. Their order of magnitude is of about $10 \%$ of the speed ratios (i.e., $\sim 0.002$ ), which gives bounds of significance for the differences in speed ratios between interior and exterior sectors. The ice-wind direction angle is calculated as the ice drift vector angle minus the wind vector angle, both with respect to the east and again in average over 1992-2005. It is thus measured in degrees, positive when the ice drift is deviated to the left with regard to the wind, and conversely.

\begin{tabular}{|c|c|c|c|c|c|c|}
\hline & & \multicolumn{5}{|c|}{ Interior sectors } \\
\hline & & Weddell & Indian & Pacific & Ross & Bel. Amun. \\
\hline \multirow{4}{*}{ Speed ratios } & NEMO-LIM3 & 0.019 & 0.018 & 0.022 & 0.019 & 0.013 \\
\hline & IPSL & 0.027 & 0.029 & 0.024 & 0.025 & 0.024 \\
\hline & CCSM4 & 0.022 & 0.022 & 0.024 & 0.016 & 0.014 \\
\hline & $\mathrm{KIM} / \mathrm{EI}$ & 0.015 & 0.013 & 0.009 & 0.015 & 0.008 \\
\hline \multirow{3}{*}{ Direction angles } & "NEMO-LIM3 & 223 & $2-6$ & 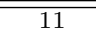 & 30 & $2-2$ \\
\hline & IPSL & 35 & 18 & 10 & 39 & 49 \\
\hline & CCSM4 & 93 & 76 & 31 & 77 & -120 \\
\hline & & \multicolumn{5}{|c|}{ Exterior sectors } \\
\hline & & Weddell & Indian & Pacific & Ross & Bel. Amun. \\
\hline \multirow{4}{*}{ Speed ratios } & NEMO-LIM3 & 0.022 & 0.021 & 0.022 & 0.023 & 0.02 \\
\hline & IPSL & 0.02 & 0.02 & 0.018 & 0.016 & 0.018 \\
\hline & CCSM4 4 & 0.023 & 0.024 & 0.025 & 0.022 & 0.022 \\
\hline & KIM/EI & 0.016 & 0.015 & 0.015 & 0.015 & 0.016 \\
\hline \multirow{3}{*}{ Direction angles } & "NEMO-LIM3 & 13 & 10 & 13 & 7 & 20 \\
\hline & IPSL & 38 & 26 & 2 & 35 & 18 \\
\hline & CCSM 4 & 20 & 16 & 5 & 31 & 32 \\
\hline
\end{tabular}


speed is overestimated and both NEMO-LIM3 and IPSL values remain close to this satellite product. These biases are different in interior sectors. Apart from the Pacific sector where all models simulate too fast ice motion, the ice drift from NEMO-LIM3 is consistent or slower than in observations. CCSM4 and IPSL then respectively overestimate the Fowler et al. (2013) ice speed by about 40 and $100 \%$.

For surface winds, IPSL and CCSM4 present norms that are 0-20\% (0-1.5 m $\left.\mathrm{s}^{-1}\right)$ and $25-50 \%\left(2-3.5 \mathrm{~m} \mathrm{~s}^{-1}\right)$ larger than the NCEP/NCAR values in exterior 290 sectors, respectively. However, the latter wind reanalysis seems to display wind speeds significantly smaller than in the ERA Interim one everywhere in the study area, except at the coasts (not shown). Consequently, while the simulated wind speeds tend to be underestimated with regard to ERA Interim, they lie within the interval of reanalyzed values delimited by the NCEP/NCAR and ERA Interim datasets, except for CCSM4 in the Weddell and BellingshausenAmundsen Seas where winds are even stronger than in ERA Interim by $1 \mathrm{~m}$ $\mathrm{s}^{-1}$. The situation in interior sectors is similar as surface wind speed in the two climate models stays between NCEP-NCAR and ERA Interim values overall, but in this region CCSM4 does not systematically simulate stronger winds than 300 IPSL. Some studies demonstrate a better performance of recent reanalyses such as ERA Interim, as compared with older ones, in simulating the atmospheric circulation at high latitudes (e.g., Bracegirdle and Marshall, 2012, Bracegirdle, 2013). Given the specific physical processes and the small amount of data in this region, no reanalysis product is to be fully trusted yet, but they still provide reliable information on the atmospheric mean state since 1979 (e.g., Bromwich et al. 2007).

In exterior regions (except the Ross Sea), the larger the difference in ice speed between on the one hand CCSM4 or IPSL and on the other hand NEMO-LIM3 or observations, the larger the difference in wind speed between the two CMIP5 310 models and NCEP/NCAR wind reanalyses. Conversely, the larger the difference in ice speed between the two climate models and NEMO-LIM3, the smaller the associated difference in wind speed with ERA-Interim. This is not valid for interior regions. There, relative differences in ice speed from climate models with either NEMO-LIM3 or Fowler et al. (2013) observations do not correspond 315 to consistent wind speed biases with respect to either NCEP/NCAR or ERA Interim reanalyses. For instance, in all interior regions, the ice moves faster in IPSL than in CCSM4, whereas the wind is actually stronger in CCSM4 in the Bellingshausen-Amundsen and Ross sectors. However, NEMO-LIM3 has both the weakest winds and the slowest ice motion everywhere.

Table 2 presents an unexpected result for the IPSL model: speed ratios in interior sectors are significantly larger than those in exterior sectors (difference larger than the typical standard deviation of speed ratios), while in the interior the sea ice internal stress is expected to be more important and should slow down the ice. This is in large part explained by the fact that the limit between 325 the interior and the exterior is not well adapted for this model. Averages are made over a relatively long autumn-winter period (April-October) when the ice edge advances north, meaning that many interior sectors are also exterior 
ones part of that time. It is particularly problematic for the IPSL model, as suggested by Fig. 1, for which the April sea ice cover is very small. The values in the interior sectors are therefore a mix of free drifting (as in the exterior sectors) and non-free drifting conditions. Given that the interior sector winds in IPSL are not significantly weaker than in exterior sectors, contrary to those in CCSM4 and NEMO-LIM3, the ice drift speed in interior sectors are much larger than expected (Fig. 5 and 6). A way to avoid this would be to re-

335 define, for each model, interior sectors as the area where ice concentration is larger than $15 \%$ during April, and exterior ones as the area between this and the maximum winter extent. We chose, however, not to do this because such a definition of these sectors presents two issues: (1) the sector-wise comparisons between models may not be consistent and (2) a model like IPSL would then

340 have almost no interior sector for instance. By contrast, NEMO-LIM3, CCSM4 and observation-based exterior speed ratios are all larger than interior ones as expected, and their values are consistent with previous observation studies (Vihma et al., 1996, Uotila et al., 2000).

\subsection{Ice drift direction and wind direction}

The regional analysis presented above for wind and ice speed is repeated for the ice drift and surface wind directions (Fig. 7). Contrary to the discrepancies in wind speed between NCEP/NCAR and ERA Interim, no substantial difference in wind direction is found between those reanalyses. The agreement between the two ice drift satellite products is also relatively good except in 350 the Indian and Pacific exterior sectors, where the direction of the simulated drift vectors in NEMO-LIM3 and CCSM4 is more consistent with Kimura et al. (2013) than Fowler et al. (2013). Although shifts in direction are more difficult to evaluate quantitatively, the consistency between ice drift and wind direction differences with respect to observations or reanalyses in exterior regions is found again here. Whenever a deviation of the ice drift in a given model is substantial with respect to either satellite observations or other models, a substantial shift in wind orientation (compared with other models or reanalyses) is also observed, and those shifts are in the same direction. As for ice and wind speed, the behavior of the various models is more complex in interior sectors where ice and wind direction shifts are not always consistent (i.e., a large ice drift shift in a given direction with respect to observations does not necessarily relate to a wind shift in the same direction with respect to reanalyses).

Table 2 also illustrates this different contribution of in ice dynamics between interior and exterior areas. In the interior, ice-wind turning angles vary widely among models and regions because the ice is not in free drift. The range is smaller in exterior sectors and turning angles vary within the uncertainty of their observed values for free drift conditions (Martinson and Wamser, 1990 Uotila et al., 2000). In these models, both the atmospheric and oceanic stresses on the ice are calculated based on the same formula representing the effect of the wind and ocean currents rotation in their respective boundary Ekman layer 
EXTERIOR SECTORS

INTERIOR SECTORS

Ice drift direction Wind direction Ice drift direction Wind direction
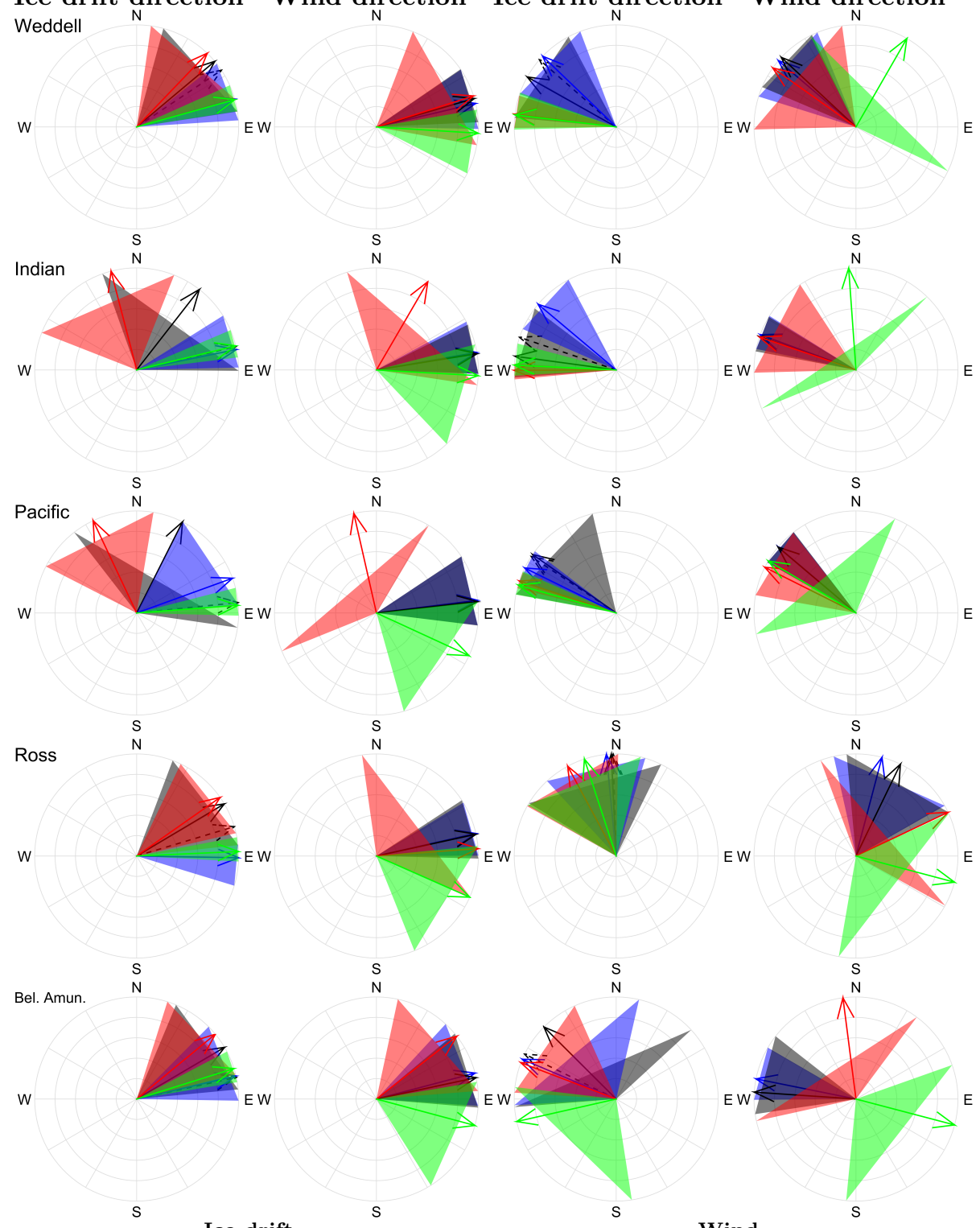

Ice drift

S

Wind

- Fowler et al. (2013) ice drift data

- Kimura et al. (2013) ice drift data

- NEMO-LIM3 ice drift

$$
\text { - IPSL }
$$

- ERA Interim wind

- NCEP/NCAR wind

- IPSL

- CCSM4

Figure 7: Mean value (colored arrows) and variation range (colored cones) of the sea ice drift direction and surface wind direction in each sector of the Southern Ocean, as defined in Fig. 4 The averages are performed over April-October 1992-2005, except for Kimura et al. (2013) ice drift data (2003-2010). The wind speeds displayed for NEMO-LIM3 are actually the NCEP/NCAR wind reanalyses used to force the model. For the sake of readability, variation ranges for the Kimura et al. (2013) ice drift data are not shown and only the mean direction is plotted using dashed arrows. 
(Leppäranta, 2011):

$$
\boldsymbol{\tau}_{\mathbf{a} / \mathbf{w}}=D_{a / w} \rho_{a / w}\left|\mathbf{U}_{\mathbf{a} / \mathbf{w}}-\mathbf{u}\right|\left[\left(\mathbf{U}_{\mathbf{a} / \mathbf{w}}-\mathbf{u}\right) \cos \theta_{a / w}+\mathbf{k} \times\left(\mathbf{U}_{\mathbf{a} / \mathbf{w}}-\mathbf{u}\right) \sin \theta_{a / w}\right]
$$

where $D_{a / w}$ is the atmosphere-ice or ocean-ice drag coefficient, $\rho_{a / w}$ the air or seawater density, $\mathbf{U}_{\mathbf{a} / \mathbf{w}}$ the wind or ocean velocity vectors and $\theta_{a / w}$ the turning angle between winds (at a given altitude) or ocean currents (at a given depth) and the corresponding surface quantities with respect to the ice. $\mathbf{k}$ is the vertical unit vector. $\theta_{w}$ is taken to zero, because the resolution in ocean models is sufficient to resolve the Ekman spiral and provides the surface currents directly to the ice (e.g., Hunke et al. 2010, Hunke and Lipscomb, 2010 Vancoppenolle et al. 2012). As for the wind stress, the ice drift speed is neglected compared to the wind speed and no turning angle is used because the surface winds are either resolved by atmospheric models (e.g., Large and Yeager, 2004) or provided by 10 $\mathrm{m}$ wind reanalyses like in NEMO-LIM3. This similar treatment of atmospheric and oceanic stresses combined with nearly identical (constant) values for the

375 associated drag coefficients in models explain why the turning angles in exterior sectors are relatively close to one another. However, they do show some regional or inter-model variability because other factors, such as the effects of the Coriolis force and ocean currents (Uotila et al., 2000, Leppäranta, 2011), come into play and may modify the turning angle with respect to the wind. In the Southern

380 Hemisphere, under free drift conditions, the ice velocity turns about 25 degrees left from the near-surface wind when ice is relatively thin and ocean currents are weak (Martinson and Wamser, 1990, Vihma et al., 1996). Thicker ice turns more from the wind, because the Coriolis force is proportional to ice thickness. Additionally, it is likely that strong eastward circumpolar ocean currents affect

385 the direction angles in the exterior sectors. In summary, despite some expected variability of the turning angles in Table 2, in exterior sectors, they all remain consistent with the similar physics for ocean and wind stresses in all models. This ultimately support that sea ice is effectively in free drift in these regions.

\section{Discussion}

An important limitation of this work is the uncertainty in ice drift observations and wind reanalyses. While the ice drift speed in the models studied here often overestimate the Fowler et al. (2013) values, like CCSM4 everywhere or IPSL in interior sectors, some of them in fact simulate a realistic ice motion compared to Kimura et al. (2013). This is the case of IPSL and NEMO-LIM3 in exterior sectors. Similar observations can be made regarding the wind in IPSL and CCSM4 and the NCEP/NCAR or ERA Interim reanalyses. Attributing biases in sea ice drift to errors in wind speeds is thus impossible based on such comparisons only. However, relating these biases to the sea ice concentration budget in each model, as it is done below, enables one to assess their realism

400 regarding their representation of the processes driving the sea ice concentration evolution. Here, we focus on the ice velocity divergence because it is the term 
in the ice concentration budget that seems systematically underestimated in all models and in both the exterior and interior regions of the Southern Ocean.

Exterior sectors. Ice velocity divergence may be wrong for three reasons: errors in ice drift speed, in ice drift direction or both. Those errors may in turn be due to a combination of wind errors, ocean current errors and wrong model physics in the ice dynamics. As shown in section 4.2 , the models with the fastest ice drift, seemingly caused by stronger winds, are also those with the smallest biases in the divergence term of the sea ice concentration budget. In terms of 410 wind direction, the agreement between NCEP/NCAR and ERA Interim wind directions in Fig. 7 gives good confidence on their reliability. Compared to them, both the IPSL and CCSM4 models seem to have systematic biases, with a leftward and rightward deviation in their winds, respectively. Thus no model is more skillful than the others in terms of wind errors only. However, those errors are both systematic (qualitatively the same in all exterior sectors of the Antarctic sea ice zone) and consistent with those in ice drift. For instance CCSM4 exhibits a rightward deviation of its winds (compared to reanalyses) and of its ice drift (compared to observations) directions in all exterior sectors. Besides, it is the model with the strongest winds and the fastest ice drift in all ${ }_{420}$ exterior regions as well. In the NEMO-LIM3 and IPSL models the ice drift is slower and as is the wind. Thus, the systematic and coherent behaviors in ice and wind speeds indicate that winds in these regions play an important role in driving the ice motion, ultimately affecting the divergence or advection biases in the ice concentration budget. This is fully consistent with the nearly free drift 425 nature of the ice motion in marginal ice zones and has distinct consequences among models. CCSM4, presenting the strongest winds and fastest ice motion, exhibits the most realistic divergence pattern in the ice concentration budget. However, even considering the previously discussed uncertainties in the ice drift satellite products (Fig. 3) and the ERA Interim winds (Fig. 6), it is still likely

430 that wind and ice drift speeds are overestimated in this model and compensate for errors in ice drift direction with respect to ice divergence. NEMO-LIM3 and IPSL then display larger errors in ice divergence because of their slower ice motion in addition to biases in ice drift direction. The intense divergence in the concentration budget of this model results in realistic sea ice freezing rates, ${ }_{435}$ also noticeable in Fig. 1. Compared to satellite observations, the wintertime ice extent increasing rate is clearly the best in CCSM4, although the mean bias over the year is the largest probably due to the too strong northward advection of sea ice. Implications of those results are that realistically simulating the ice velocity divergence, thanks to correct winds or boundary layer physics, in the marginal sea ice zone of the southern hemisphere deeply impacts on the ice growth and on the late winter sea ice extent maximum.

Interior sectors. The relationship between ice velocity, ice velocity divergence and wind errors in interior regions of the Southern Ocean is different from the one in exterior sectors. Interior sectors exhibit errors in ice drift (speed and 445 direction) that are not simply linked to model-reanalysis or inter-model wind differences. The sea ice cover is packed there and undergoes large mechanical constraints. The VP and EVP models for sea ice rheology have been shown to 
produce different sea ice dynamic responses to a forcing on a daily timescale (Hunke and Dukowicz, 1997; Hunke and Zhang, 1999, Bouillon et al., 2013). Therefore, the sea ice motion in response to the wind forcing in these regions is affected by the rheologies used for sea ice and expectedly displays more complex drift error patterns than just those potentially induced by winds.

Again, the errors can be connected to specific signatures in the ice concentration budget. Near the coast of Antarctica (see Fig. 5 and 6), IPSL has the

455 fastest ice drift compared to other models. The associated winds in the model are also strong but comparable to ERA Interim values in the corresponding sectors. Because the ice is somehow too mobile, it results in locally strong advection patterns (Fig. 2), in turn driving the accelerated retreat of the sea ice in late winter and spring, observable in Fig. 1. In contrast, the ice is much slower in NEMO-LIM3, which exhibits the largest ice velocity divergence errors in the interior sectors, except very close to the coast. Too slow ice motion may explain the late ice break up near the coast in early summer in NEMO-LIM3. This may in turn be due to both weak winds (Fig. 6) and too strong ice rigidity in its rheology formulation. Over the year, deficient summer melt and insufficient

465 winter growth rate lead to a smaller seasonality of the ice extent for this model (Fig. 1). In yearly average, the sea ice extent produced by NEMO-LIM3 is thus the closest to observations, but it is partly due to error compensations between delayed ice melt in summer and underestimated ice growth rates in winter. In CCSM4, wind speed seems more realistic than in NEMO-LIM3, yet the com470 pact ice pack in interior sectors is too rigid to break up and melt away, resulting in a largely overestimated sea ice extent summer minimum. In summary, the respective contributions of wind biases and incorrect model physics to errors in ice drift (speed and direction) in the studied simulations seem to be both important.

\section{Conclusion}

We derive the terms in the Antarctic sea ice concentration budget from the output of three models, and compare them to observations of the same terms. One model is a global ocean-sea ice coupled model with prescribed atmosphere (NEMO-LIM3) and the two others are fully coupled climate models (CCSM4 480 and IPSL) that were part of the CMIP5 initiative. In order to identify the origins of the errors in the different terms of the ice concentration budget, both the sea ice drift and wind fields from each model were inter-compared and analyzed using two sets of ice motion vector satellite observations (Fowler et al. 2013: Kimura et al., 2013) and two datasets of wind reanalyses (NCEP/NCAR

485 and ERA Interim). This work represents an additional step with respect to the study of Uotila et al. (2014), who applied the same budget analysis to one model without analyzing the potential links with wind biases. Results show important differences in the ice concentration budgets and the ice drift/wind speed relationships of the three chosen models, which justifies a detailed analysis 
The sole assessment of the model wind and ice drift biases does not allow to evaluate them in terms of their simulation skills. Indeed, the wind speeds they simulate often fall in the interval of plausible values defined by the NCEP/NCAR and ERA Interim reanalyses, and although the simulated ice drift is sometimes out of the Fowler et al. (2013) -Kimura et al. (2013) range of values (e.g., CCSM4 in exterior sectors, or IPSL and CCSM4 in the interior), the uncertainty on ice drift satellite observations remains very large. This illustrates the common difficulty of applying such diagnostics directly comparing variables from complex models to observations. The observable biases largely 500 vary between regions and, generally, no model is systematically better than the other ones, everywhere and for all variables. Here, we showed the particular suitability of a process-oriented diagnostic such as the ice concentration budget, combined with regular model-observation diagnostics, for discriminating the origins of systematic and dynamically-driven errors in the ice concentration evolution.

Systematic biases are found in all models, although with behaviors near the Antarctic coast that are distinct from those in the central and outer pack where the ice is close to free drift. In the latter regions, models with the weakest winds exhibit as well the slowest ice motion and the smallest velocity divergence and 510 freezing rates in the ice concentration budget. This, in turn, impacts on the overall sea ice expansion rate in winter. Closer to coastal areas, the faster the ice motion, the most rapid its early summer retreat. However, the consistent relationship between these biases and those in wind speed in those interior regions is less prominent than in exterior, marginal ice regions. Because the

515 ice is more compact and under greater mechanical constraints locally, errors in ice drift in models may be attributed to an inappropriate treatment of the ice rheology just as well as errors in wind speed or direction.

Therefore, although the present study is not able to precisely quantify the respective contributions of wind biases and model physics to ice divergence or 520 advection errors in the sea ice concentration budget, it provides a baseline for a categorization of climate models in terms of the relationship between those errors. The distinction can be made between models lacking sea ice velocity divergence and hence demonstrating issues in reproducing the wintertime sea ice growth and maximum extent, from those unrealistically simulating the ice 525 advection in coastal locations, hindering or accelerating the summertime retreat and melting of the ice. For instance, lacking ice velocity divergence in IPSL, in part due to incorrect winds in exterior regions of the Southern Ocean, leads to an underestimated winter sea ice extent. Then during late winter in interior sectors, too fast ice drift subserves a fast break up and melt of the ice. In 530 CCSM4, divergence-led freezing in the ice concentration budget is more realistic, but an overestimated advection brings the ice cover too far northwards due to presumably too strong winds in exterior regions. As a result, the high bias of $5 \times$ $10^{6} \mathrm{~km}^{2}$ in ice extent at the end of the growth season remains present throughout the summer. NEMO-LIM3, although in better agreement with observations in 535 yearly average if only looking at the sea ice extent, yields too slow ice motion in the south Weddell and Ross Seas that are forced by the weakest winds of all 
models as well. Consequently, underestimated winter freezing rates associated with weak ice velocity divergence are in yearly average compensated by the delayed break up and melt of sea ice. This is, however, without considering any of the potential model biases in the sea ice thermodynamics or oceanic surface currents that may amplify or mask biases in ice dynamics. In this respect, the ice concentration budget is one part of a model global assessment. For instance, an ice thickness budget would also be a very valuable complement to this analysis provided that an observational equivalent of such a budget were available, which ${ }_{545}$ is not the case at present time.

Thus, this method gives insight on prioritizing models improvement or evaluation. Except in regions where sea ice is nearly in free drift (ice there undergoes almost no deformation), its drift for a given wind forcing is largely influenced by the ice rheology used in the model. Following steps would be implementing new generation rheologies (e.g., Bouillon et al., 2009; Sulsky and Peterson 2011; Wilchinsky and Feltham, 2012; Tsamados et al., 2013: Dansereau et al. 2014) into climate models and re-apply our methodology to assess whether such new physics improves the ice drift and the ice concentration budget terms in mechanically constrained regions near the coast of Antarctica. Improving the 555 ice-atmosphere boundary layer physics through the use of variable atmospheric drag coefficient parameterizations (e.g., Tsamados et al., 2014), for instance, may on the other hand affect the sea ice dynamics in all Antarctic sea ice covered regions. Regarding models specifically missing ice velocity divergence in winter, a thorough evaluation of local winds in their atmospheric component may also be required. For models running under prescribed atmospheric forcing, the ice drift-wind combined assessment proposed here may as well be used for selecting the most suitable surface wind reanalysis in the sea ice covered regions of the Southern Ocean. Finally, this illustrates how the method provides a valuable analysis and evaluation tool for the Southern Ocean sea ice component in models from future CMIP phases.

\section{Acknowledgements}

We acknowledge the World Climate Research Programme's Working Group on Coupled Modelling, which is responsible for CMIP, and we thank the climate modeling groups (listed in Table 1 of this paper) for producing and mak570 ing available their model output. For CMIP the U.S. Department of Energy's Program for Climate Model Diagnosis and Intercomparison provides coordinating support and led development of software infrastructure in partnership with the Global Organization for Earth System Science Portals. We thank Antoine Barthélemy for producing and providing the NEMO-LIM3 simulation 575 used in this study and three anonymous reviewers for comments that helped to improve this manuscript. Computational resources for this simulation have been provided by the supercomputing facilities of the Université catholique de Louvain (CISM/UCL) and the Consortium des Equipements de Calcul Intensif en Fédération Wallonie Bruxelles (CECI) funded by the Fonds de la Recherche 

toral Researcher and Research Director with the Fonds National de la Recherche Scientifique (F.R.S.-FNRS-Belgium). This work was supported by FNRS Research Project "Amélioration de la représentation de la glace de mer antarctique dans les modèles climatiques grâce à une meilleure compréhension des ment $n^{\circ}$ T.0007.14. The work of P. U. was supported by the Academy of Finland (contracts 264358 and 283034).

\section{References}

Barthélemy, A., Fichefet, T., Goosse, H., Madec, G., 2015. Modeling the interplay between sea ice formation and the oceanic mixed layer: Limitations of simple brine rejection parameterizations. Ocean Modelling 86, 141-152.

Bitz, C., Holland, M., Hunke, E., Moritz, R., 2005. Maintenance of the sea-ice edge. Journal of climate 18, 2903-2921.

Bouillon, S., Fichefet, T., Legat, V., Madec, G., 2013. The elastic-viscousplastic method revisited. Ocean Modelling 71, 2-12.

Bouillon, S., Morales Maqueda, M., Legat, V., Fichefet, T., 2009. An elasticviscous-plastic sea ice model formulated on Arakawa B and C grids. Ocean Modelling 27, 174-184. doi $10.1016 /$ j.ocemod.2009.01.004.

Bracegirdle, T.J., 2013. Climatology and recent increase of westerly winds over the Amundsen Sea derived from six reanalyses. International Journal of Climatology 33, 843-851.

Bracegirdle, T.J., Marshall, G.J., 2012. The reliability of Antarctic tropospheric pressure and temperature in the latest global reanalyses. Journal of Climate 25, 7138-7146.

Bromwich, D.H., Fogt, R.L., Hodges, K.I., Walsh, J.E., 2007. A tropospheric assessment of the ERA-40, NCEP, and JRA-25 global reanalyses in the polar regions. Journal of Geophysical Research-Atmospheres 112.

Cavalieri, D., Parkinson, C., Gloersen, P., Zwally, H.J., 1996, updated yearly. Sea Ice Concentrations from Nimbus-7 SMMR and DMSP SSM/I-SSMIS Passive Microwave Data, Version 1. NASA National Snow and Ice Data Center Distributed Active Archive Center, Boulder, Colorado USA .

Comiso, J.C., 2000, updated 2015. Bootstrap Sea Ice Concentrations from Nimbus-7 SMMR and DMSP SSM/I-SSMIS, Version 2. NASA National Snow and Ice Data Center Distributed Active Archive Center, Boulder, Colorado USA .

Comiso, J.C., Kwok, R., Martin, S., Gordon, A.L., 2011. Variability and trends in sea ice extent and ice production in the Ross Sea. Journal of Geophysical Research - Oceans 116. 
Dansereau, V., Weiss, J., Saramito, P., 2014. A Maxwell-Elasto-Brittle rheology for sea ice modeling. Mercator Ocean Newsletter 51.

Dee, D., Uppala, S., Simmons, A., Berrisford, P., Poli, P., Kobayashi, S., Andrae, U., Balmaseda, M., Balsamo, G., Bauer, P., et al., 2011. The ERAInterim reanalysis: Configuration and performance of the data assimilation system. Quarterly Journal of the Royal Meteorological Society 137, 553-597.

625 Fichefet, T., Morales Maqueda, M., 1997. Sensitivity of a global sea ice model to the treatment of ice thermodynamics and dynamics. Journal of Geophysical Research-Oceans 102.

Fowler, C., Maslanik, J., Emery, W., Tschudi, M., 2013. Polar Pathfinder Daily 25 km EASE-Grid Sea Ice Motion Vectors, version 2, Southern Hemisphere. Boulder, Colorado, USA: National Snow and Ice Data Center .

Gent, P.R., Danabasoglu, G., Donner, L.J., Holland, M.M., Hunke, E.C., Jayne, S.R., Lawrence, D.M., Neale, R.B., Rasch, P.J., Vertenstein, M., Worley, P.H., Yang, Z.L., Zhang, M., 2011. The community climate system model version 4. Journal of Climate 24, 4973-4991.

635 Goosse, H., 1997. Modeling the large-scale behavior of the coupled ocean-sea ice system. Ph.D. thesis, 231 pp., Univ. Catholique de Louvain, Louvain-laNeuve, Belgium. .

Heil, P., Fowler, C.W., Maslanik, J.A., Emery, W.J., Allison, I., 2001. A comparison of East Antarctic sea-ice motion derived using drifting buoys and remote sensing. Annals of Glaciology 33, 139-144.

Hibler, W., 1979. A dynamic thermodynamic sea ice model. Journal of Physical Oceanography 9, 815-846.

Holland, P., Noriaki, K., Submitted. Observed concentration budgets of Arctic and Antarctic sea ice. Journal of climate .

${ }_{645}$ Holland, P.R., Kwok, R., 2012. Wind-driven trends in Antarctic sea-ice drift. Nature Geoscience 5, 872-875.

Hunke, E., Dukowicz, J., 1997. An elastic-viscous-plastic model for sea ice dynamics. Journal of Physical Oceanography 27, 1849-1867.

Hunke, E., Lipscomb, W., 2010. CICE: the Los Alamos sea ice model, documentation and software user's manual, Version 4.1 .

Hunke, E., Lipscomb, W., Turner, A., 2010. Sea-ice models for climate study: retrospective and new directions. Journal of Glaciology 56, 1162-1172.

Hunke, E., Zhang, Y., 1999. A comparison of sea ice dynamics models at high resolution. Monthly Weather Review 127, 396-408. 
Kalnay, E., Kanamitsu, M., Kistler, R., Collins, W., Deaven, D., Gandin, L., Iredell, M., Sana, S., White, G., Woollen, J., et al., 1996. The NCEP/NCAR 40-Year Reanalysis Project. Bulletin-American Meteorological Society 77, $437-471$.

Kimura, N., Nishimura, A., Tanaka, Y., Yamaguchi, H., 2013. Influence of winter sea ice motion on summer ice cover in the Arctic. Polar Research 32, 20193.

Kwok, R., Schweiger, A., Rothrock, D., Pang, S., Kottmeier, C., 1998. Sea ice motion from satellite passive microwave imagery assessed with ERS SAR and buoy motions. Journal of Geophysical Research - Oceans 103, 8191-8214.

Landrum, L., Holland, M.M., Schneider, D.P., Hunke, E., 2012. Antarctic sea ice climatology, variability, and late twentieth-century change in CCSM4. Journal of Climate 25, 4817-4838.

Large, W., Yeager, S., 2004. Diurnal to decadal global forcing for ocean and sea-ice models: the data sets and flux climatologies .

Leppäranta, M., 2011. The drift of sea ice. Springer Science \& Business Media.

Madec, G., 2008. NEMO ocean engine: Note du Pole de Modelisation, Institut Pierre-Simon Laplace URL: http://www.nemo-ocean.eu/About-NEMO/ Reference-manuals.

Mahlstein, I., Gent, P.R., Solomon, S., 2013. Historical Antarctic mean sea ice 675 area, sea ice trends, and winds in CMIP5 simulations. Journal of Geophysical Research: Atmospheres 118, 5105-5110.

Marshall, G.J., 2003. Trends in the Southern Annular Mode from observations and reanalyses. Journal of Climate 16, 4134-4143.

Martinson, D.G., Wamser, C., 1990. Ice drift and momentum exchange in winter 680 Antarctic pack ice. Journal of Geophysical Research-Oceans 95, 1741-1755.

OSISAF, E., 2010. Global sea ice concentration reprocessing dataset 1978-2007 (v1), http://osisaf.met.no .

Randall, D.A., Wood, R.A., Bony, S., Colman, R., Fichefet, T., Fyfe, J., Kattsov, V., Pitman, A., Shukla, J., Srinivasan, J., et al., 2007. Climate models and their evaluation, in: Climate Change 2007: The physical science basis. Contribution of Working Group I to the Fourth Assessment Report of the IPCC (FAR). Cambridge University Press, pp. 589-662.

Sulsky, D., Peterson, K., 2011. Toward a new elastic-decohesive model of Arctic sea ice. Physica D: Nonlinear Phenomena 240, 1674-1683.

${ }_{690}$ Taylor, K.E., Stouffer, R.J., Meehl, G.A., 2012. An overview of CMIP5 and the experiment design. Bulletin of the American Meteorological Society 93, $485-498$. 
Thorndike, A., Rothrock, D., Maykut, G., Colony, R., 1975. The thickness distribution of sea ice. Journal of Geophysical Research 80, 4501-4513.

695 Tsamados, M., Feltham, D.L., Schroeder, D., Flocco, D., Farrell, S.L., Kurtz, N., Laxon, S.W., Bacon, S., 2014. Impact of Variable Atmospheric and Oceanic Form Drag on Simulations of Arctic Sea Ice. Journal of Physical Oceanography 44, 1329-1353.

Tsamados, M., Feltham, D.L., Wilchinsky, A.V., 2013. Impact of a new anisotropic rheology on simulations of Arctic sea ice. Journal of Geophysical Research: Oceans 118, 91-107.

Turner, J., Bracegirdle, T.J., Phillips, T., Marshall, G.J., Hosking, J.S., 2013. An initial assessment of Antarctic sea ice extent in the CMIP5 models. Journal of Climate 26, 1473-1484.

Uotila, J., Vihma, T., Launiainen, J., 2000. Response of the Weddell Sea pack ice to wind forcing. Journal of Geophysical Research-Oceans 105, 1135-1151.

Uotila, P., Holland, P.R., Vihma, T., Marsland, S.J., Kimura, N., 2014. Is realistic Antarctic sea-ice extent in climate models the result of excessive ice drift? Ocean Modelling 79, 33-42.

Vancoppenolle, M., Bouillon, S., Fichefet, T., Goosse, H., Lecomte, O., Morales Maqueda, M., Madec, G., 2012. LIM, The Louvain-la-Neuve sea Ice Model. Notes du Pôle de modélisation, Institut Pierre-Simon Laplace (IPSL), France

Vancoppenolle, M., Fichefet, T., Goosse, H., Bouillon, S., Madec, G., Maqueda, M., 2009. Simulating the mass balance and salinity of Arctic and Antarctic sea ice. 1. Model description and validation. Ocean Modelling 27, 33-53.

Vihma, T., Launiainen, J., Uotila, J., 1996. Weddell Sea ice drift: Kinematics and wind forcing. Journal of Geophysical Research-Oceans 101, 18279-18296.

Wilchinsky, A.V., Feltham, D.L., 2012. Rheology of discrete failure regimes of anisotropic sea ice. Journal of physical oceanography 42, 1065-1082.

Zhang, Z., Vihma, T., Stössel, A., Uotila, P., 2015. The role of wind forcing from operational analyses for the model representation of Antarctic coastal sea ice. Ocean Modelling 94, 95-111.

Zunz, V., Goosse, H., Massonnet, F., 2013. How does internal variability influence the ability of CMIP5 models to reproduce the recent trend in Southern Ocean sea ice extent? The Cryosphere 7. 